\title{
Diagnostic value of medical thoracoscopy in malignant pleural effusion induced by non-Hodgkin's lymphoma
}

\author{
ZHEN WANG $^{1^{*}}$, YAN-BING WU ${ }^{1 *}$, LI-LI XU ${ }^{1}$, MU-LAN JIN ${ }^{2}$, XIAO-LI DIAO ${ }^{2}$, \\ XIAO-JUAN WANG ${ }^{1}$, ZHAO-HUI TONG ${ }^{1}$ and HUAN-ZHONG SHI ${ }^{1}$ \\ Departments of ${ }^{1}$ Respiratory and Critical Care Medicine and ${ }^{2}$ Pathology, Beijing Institute of Respiratory Medicine \\ and Beijing Chaoyang Hospital, Capital Medical University, Beijing 100020, P.R. China
}

Received April 5, 2016; Accepted June 21, 2016

DOI: $10.3892 / 01.2017 .7226$

\begin{abstract}
Malignant pleural effusion (MPE) appears in up to $20 \%$ of patients with non-Hodgkin's lymphoma (NHL). The present study aimed to assess the efficacy of medical thoracoscopy (MT) in the diagnosis of patients with MPE induced by NHL. Between July 2005 and June 2014, 833 patients with pleural effusions of unknown etiology underwent MT in Beijing Chaoyang Hospital (Beijing, China), where diagnostic thoracocentesis or/and blind pleural biopsy had failed to yield an answer. Demographic, radiographic, thoracoscopic, histological and immunophenotyping data of 10 NHL patients with MPE were then retrospectively analyzed. Under medical thoracoscopy, pleural nodules (in $n=6$ patients), hyperemia $(n=5)$, plaque-like lesions $(n=4)$, pleural thickening $(n=3)$, cellulose $(n=3)$, ulcer $(n=2)$, adhesion $(n=2)$, and scattered hemorrhagic spots $(n=1)$ were observed on the surface of parietal pleura. Histopathological and immunohistochemical analysis of pleural biopsy samples led to a correct diagnosis of B-cell NHL in 7 patients and T-lymphoblastic NHL in 2 patients. Data from the present study demonstrated that pleural biopsy through MT achieved a definite diagnosis of NHL in 9 out of $10(90 \%)$ patients with MPE induced by NHL. Therefore, MT is a useful method for diagnosing MPE induced by NHL.
\end{abstract}

\section{Introduction}

Malignancies of any organ can metastasize to the pleura and induce malignant pleural effusion (MPE); however, the most frequent are lung and breast carcinomas, and lymphomas,

Correspondence to: Dr Huan-Zhong Shi, Department of Respiratory and Critical Care Medicine, Beijing Institute of Respiratory Medicine and Beijing Chaoyang Hospital, Capital Medical University, 8 Gongti Nanlu, Chaoyang, Beijing 100020, P.R. China

E-mail: shihuanzhong@sina.com

${ }^{*}$ Contributed equally

Key words: diagnosis, malignant pleural effusion, non-Hodgkin's lymphoma, pleural biopsy, thoracoscopy with MPE occurring in digestive and ovary carcinomas less frequently (1). In $\sim 10 \%$ of patients with undiagnosed pleural effusion, a lymphoma is finally detected (2). MPE is observed in $10-30 \%$ of patients with Hodgkin lymphoma at presentation (3-5) and may be upwards of 60\% (6). MPE is not uncommon in patients with non-Hodgkin's lymphoma (NHL), with a reported frequency of up to $20 \%(7,8)$. Although pleural involvement by systemic lymphoma is relatively common, primary pleural lymphoma is rare, accounting for only $7 \%$ of lymphoma cases (9). Two types of primary pleural lymphomas have been described: Body-cavity-based lymphoma seen in patients with human immunodeficiency virus infection $(10,11)$ and pyothorax-associated lymphoma in those with tuberculosis (12). In addition, an extremely rare type of primary pleural lymphoma, seen in immunocompetent patients without history of pyothorax, has been reported in case studies in the literature (13-15).

Between July 2005 and June 2014, 42 patients with MPE induced by NHL, whose major clinical presentation was pleural involvement, presented to Beijing Institute of Respiratory Medicine and Beijing Chaoyang Hospital, Capital Medical University (Beijing, China). Medical history, clinical presentation, chest imaging and investigation of thoracentesis and/or closed pleural biopsy are the basic initial studies that lead to a diagnosis in the majority of patients with MPE induced by NHL. However, in 10 of the 42 patients in the present study, a diagnosis of NHL presenting with MPE was not completely supported by the aforementioned procedures. Medical thoracoscopy (MT) followed by pathological and immunohistochemical analysis of pleural biopsy led to a correct diagnosis of NHL in 9/10 of these patients, suggesting that MT may be a logical approach allowing for the achievement of an efficient diagnosis when NHL presents as MPE. In the present study, the outcome of MT in the diagnosis of MPE induced by NHL was analyzed.

\section{Patients and methods}

Patients. Between July 2005 and June 2014, 833 patients with undiagnosed exudative pleural effusions underwent MT in Beijing Chaoyang Hospital (Beijing, China), and their detailed medical history, clinical presentation, laboratory examination 
results and imaging data were recorded (16). Prior to MT, all patients underwent the initial diagnostic workup, which included a thoracic computed tomography (CT) scan, thoracentesis and/or pleural biopsy, and their pleural effusions remain undiagnosed. In the present study, a retrospective cohort of 10 patients with MPE induced by NHL is reviewed.

The study protocol was approved by the Institutional Review Board for Human Studies of Beijing Chaoyang Hospital.

Thoracoscopic procedures. MT was performed by chest physicians in the pulmonary procedural suite of Beijing Chaoyang Hospital, as described previously $(17,18)$. Once written informed consent was obtained, the patient was positioned with the affected side up in the lateral decubitus position. The patient breathed spontaneously with supplemental oxygen via nasal cannula as required. An Aloka Ultrasound system (Hitachi Aloka Medical Ltd., Tokyo, Japan) was used to confirm the presence of effusion and evaluate the best trocar entry site, generally located at the mid-to-anterior axillary line, between the sixth and eighth intercostal spaces.

Under moderate sedation using fentanyl and midazolam, the skin, subcutaneous tissue, adjacent ribs, and parietal pleura were anesthetized with $1 \%$ lidocaine $(15-30 \mathrm{ml})$ and a small incision was made at the planned site of entry. An 8-mm disposable trocar was then inserted, and a semi-rigid thoracoscope (LTF-240, Olympus Corporation, Tokyo, Japan) was introduced into the pleural space once the fluid was completely drained. A detailed inspection of the pleural cavity was then performed, with any abnormalities documented by photographic and/or video recordings. Biopsies were performed using flexible forceps under direct visual control in all suspect areas, systematically in several regions of the parietal pleura.

At the end of the procedure, a $24 \mathrm{~F}$ chest drain was inserted for drainage. Chest radiographs were routinely obtained following the procedure and were re-checked until the chest tube was removed.

Hematoxylin and eosin $(H \& E)$ staining. Pleural biopsy samples were all paraffin embedded. The paraffin sections $(4 \mu \mathrm{m})$ were dewaxed in room temperature by 2 changes of $100 \%$ xylene for $10 \mathrm{~min}$ each, and then re-hydrated in 2 changes of $100 \%$ alcohol for $5 \mathrm{~min}$ each, and then in $95 \%$ alcohol for $2 \mathrm{~min}$ and $70 \%$ alcohol for $2 \mathrm{~min}$. Finally, wash the slides briefly in distilled water for the following experiment. For routing H\&E staining, slides were put into hematoxylin (ZLI-9615) for $8 \mathrm{~min}$ and then washed twice before incubating with eosin (ZLI-9613) for $1 \mathrm{~min}$. Finally, the slides were sealed with neutral gum.

Immunohistochemistry. Slides were placed into antigen repair buffer (pH 9.0) (ZLI-9079; 1:50 diluted in distilled water) and boiled to $95-100^{\circ} \mathrm{C}$ for $10 \mathrm{~min}$, cooled down to room temperature and washed twice in PBS. All the sections were incubated at room temperature with $3 \% \mathrm{H}_{2} \mathrm{O}_{2}$ for 10 min to block endogenous peroxidase. The slides were sealed with $1.0 \%$ bovine serum albumin (BSA, A8010; Beijing Solarbio Science \& Technology Co., Ltd., Beijing, China) for $30 \mathrm{~min}$ at room temperature. The sections were incubated with the primary antibodies (all 1:100; diluted in 1\% BSA): Mouse anti-human CD20 (ZM-0039); CD3 (ZM-0417); CD5 (ZM-0280); CD10 (ZM-0283); CD21 (ZM-0040); CD23 (ZM-0273); CYCLIND1 (ZM-0366); BCL2 (ZM-0010); BCL6 (ZM-0011); CD30 (ZM-0043); Ki67 (ZM-0165); paired box gene 5 (ZM-0466); thyroid transcription factor 1 (ZM-0250); creatine kinase (ZM-0069); creatine kinase 19 (ZM-0074); rabbit anti human CD 79a (ZA-0293), MUM1 (ZA-0583); CD138 (ZA-0584); Calretinin (ZA-0026); synapsin (RAB-0155) and terminal deoxynucleotidyl transferase (ZA-0625), respectively, overnight at $4^{\circ} \mathrm{C}$. After incubating with $\mathrm{PBS}$ three times, horseradish peroxidase (HRP)-conjugated secondary antibodies (1:300; diluted in $1 \%$ BSA): HRP-conjugated goat anti mouse IgG (ZDR-5307) or HRP-conjugated goat anti rabbit IgG (ZDR-5306) were applied to the slides and incubated for $1 \mathrm{~h}$ at room temperature. The slides were developed with DAB (ZLI-9019; 1:20 diluted in DAB substrate supplied within the kit) for $10 \mathrm{~min}$ at room temperature, and then rinsed in running tap water for $5 \mathrm{~min}$. Subsequently, $0.5 \%$ hematoxylin (ZLI-9615) was used to stain the samples at room temperature for $8 \mathrm{~min}$, then washed twice and sealed with neutral gum. All slides were examined carefully under a light microscope at magnification, x400. All the $\mathrm{H} \& \mathrm{E}$ staining and immunohistochemistry reagents mentioned above were from Zhongshan Golden Bridge Biotechnology, Co., Ltd (Beijing, China), except for synapsin (RAB-0155), which was obtained from Maxim Biotechnology, Co., Ltd (Fuzhou, China).

Diagnosis of NHL. A histopathological and immunohistochemical review of all slides with at least one paraffin block representative pleural biopsy samples obtained through MT. The diagnosis of NHL was established by pathologists according to the current guidelines $(19,20)$.

Statistical analysis. Data are presented as the mean \pm standard deviation or number with percentage. Descriptive statistical methods were used for data analysis with SPSS version 16.0 Statistical Software (SPSS, Inc., Chicago, IL, USA).

\section{Results}

Clinical data. A total of 833 patients with undiagnosed pleural effusions successfully underwent MT between July 2005 and June 2014 (16). MPE was the final diagnosis in 342 (41.1\%) patients with lymphocytic exudates and 10 patients with MPE were diagnosed with NHL.

All 10 NHL patients with MPE had no history of tuberculosis and serological tests found that they were negative for human immunodeficiency virus. As shown in Table I, the most common symptom was dyspnea $(n=8)$; the other symptoms included cough $(n=4)$, fever $(n=2)$, chest pain $(n=1)$ and weight loss $(n=1)$. Lymph nodes were readily palpable in a single patient. A diagnosis of metastatic carcinoma or inflammatory disease was initially proposed in each instance.

Radiographic findings. Pleural effusions were bilateral in 3 patients. In the other 7 patients, effusions were in the right hemithorax in 4 patients and in the left hemithorax in 3 patients (Table I). The volume of a pleural effusion was estimated as small, moderate or large based on CT imaging, according to 
Table I. Clinical characteristics of the study population.

\begin{tabular}{|c|c|c|c|c|c|c|c|c|}
\hline Patient no. & Sex & $\begin{array}{l}\text { Age, } \\
\text { years }\end{array}$ & Smoking status & $\begin{array}{l}\text { Tuberculosis } \\
\text { history }\end{array}$ & $\begin{array}{l}\text { HIV } \\
\text { status }\end{array}$ & $\begin{array}{l}\text { Effusion } \\
\text { site }\end{array}$ & $\begin{array}{l}\text { Effusion } \\
\text { size }\end{array}$ & Main symptoms \\
\hline 1 & M & 56 & Current smoker & No & Negative & Left & Large & Dyspnea, fever \\
\hline 2 & M & 71 & Non-smoker & No & Negative & Right & Large & Dyspnea, cough \\
\hline 3 & M & 76 & Ex-smoker & No & Negative & Bilateral & Small & Chest pain \\
\hline 4 & $\mathrm{~F}$ & 59 & Non-smoker & No & Negative & Right & Large & Dyspnea \\
\hline 5 & M & 66 & Current smoker & No & Negative & Left & Large & Dyspnea, fatigue \\
\hline 6 & M & 60 & Current smoker & No & Negative & Left & Small & Dyspnea \\
\hline 7 & M & 54 & Non-smoker & No & Negative & Bilateral & Large & Dyspnea, cough \\
\hline 8 & M & 30 & Non-smoker & No & Negative & Right & Moderate & Dyspnea, cough, fever \\
\hline 9 & M & 53 & Current smoker & No & Negative & Bilateral & Large & Dyspnea, cough \\
\hline 10 & M & 73 & Current smoker & No & Negative & Right & Moderate & $\begin{array}{l}\text { Weight loss, multiple } \\
\text { lymphadenopathy }\end{array}$ \\
\hline
\end{tabular}

HIV, human immunodeficiency virus.

Table II. Chest computed tomography scan findings $(n=10)$.

\begin{tabular}{|c|c|c|c|c|c|c|c|c|c|c|c|}
\hline \multirow[b]{2}{*}{ Finding } & \multicolumn{10}{|c|}{ Patient no. } & \multirow[b]{2}{*}{ Total, $\mathrm{n}$} \\
\hline & 1 & 2 & 3 & 4 & 5 & 6 & 7 & 8 & 9 & 10 & \\
\hline Pleural effusion & + & + & + & + & + & + & + & + & + & + & 10 \\
\hline Diffuse pleural thickening & & + & & + & & & & + & + & + & 5 \\
\hline Focal pleural thickening & + & & + & + & + & & + & & & & 5 \\
\hline Pleural nodules & & & & + & + & & & + & & & 3 \\
\hline Pleural masses & & & & + & & & & + & & & 2 \\
\hline Pulmonary consolidation or infiltration & & & + & & & + & + & + & + & + & 6 \\
\hline Thoracic lymphadenopathy & & & & + & & & + & + & & + & 4 \\
\hline Lung nodule or mass & & & + & + & & & & + & & & 3 \\
\hline Obstructive atelectasis & & & & & & & & + & & & 1 \\
\hline Pericardial effusion & & & & & & & & & & + & 1 \\
\hline Abdominal lymphadenopathy & + & & & + & + & & & + & + & + & 6 \\
\hline Abdominal mass & & & & & & & & & & + & 1 \\
\hline Hepatomegaly & & & & & & & & & & + & 1 \\
\hline Liver metastases & & & & & & & & & + & & 1 \\
\hline Overall, $\mathrm{n}$ & 3 & 2 & 4 & 8 & 4 & 2 & 4 & 9 & 5 & 8 & \\
\hline
\end{tabular}

the techniques described by Moy et al (21). In either unilateral or bilateral effusion, the volume of pleural effusions was small in 2 patients, moderate in 2, and large in 6.

In addition to pleural effusion, CT scan (Table II) following administration of intravenous contrast medium revealed diffuse pleural thickening $(n=5)$, focal pleural thickening $(n=5)$, pleural nodules $(n=3)$, and pleural masses $(n=2)$. Isolated pleural effusion with no demonstrable pleural thickening or mass could also be seen. No patients had evidence of visceral pleural abnormalities on CT scan. Other pulmonary involvements included pulmonary consolidation or infiltration $(n=6)$, thoracic lymphadenopathy $(n=4)$, lung nodule or mass $(n=3)$, and obstructive atelectasis $(n=1)$.
Subsequent CT examination of the abdomen revealed other previously undetected abnormalities, including abdominal lymphadenopathy $(n=6)$, abdominal mass $(n=1)$, hepatomegaly $(\mathrm{n}=1)$, and liver metastasis $(\mathrm{n}=1)$.

Thoracoscopic results. Thoracentesis showed the appearance of pleural fluid was bloodstained in 5 patients, and yellow in the remaining 5 patients. According to Light's criteria (22), exudative pleural effusions were observed in all 10 patients, with $48.1 \pm 19.9 \mathrm{~g} / \mathrm{l}$ total protein and $185 \pm 45$ IU/1 lactate dehydrogenase (Table III). The concentration of glucose in pleural fluid was $5.69 \pm 2.33 \mathrm{mmol} / 1$ (corresponding serum glucose was $5.42 \pm 1.81 \mathrm{mmol} / \mathrm{l})$. The pleural fluid leukocyte count 
Table III. Characteristics of pleural fluid.

\begin{tabular}{|c|c|c|c|c|c|c|c|c|c|}
\hline Patient no. & $\begin{array}{c}\text { Effusion } \\
\text { appearance }\end{array}$ & $\begin{array}{l}\text { Effusion } \\
\text { nature }\end{array}$ & $\begin{array}{l}\text { Protein, } \\
\mathrm{g} / 1\end{array}$ & $\begin{array}{l}\mathrm{LDH}, \\
\mathrm{IU} / 1\end{array}$ & $\begin{array}{l}\text { Glucose, } \\
\mathrm{mmol} / \mathrm{l}\end{array}$ & $\begin{array}{l}\text { Cell counts } \\
\times 10^{9} / 1\end{array}$ & $\begin{array}{c}\text { Lymphocytes, } \\
\%\end{array}$ & $\begin{array}{l}\text { Mycobacterial smear } \\
\text { and culture }\end{array}$ & $\begin{array}{l}\text { Malignant } \\
\text { cells }\end{array}$ \\
\hline 1 & Blood-stained & Exudative & 93.4 & 99 & 5.87 & 3.30 & 88 & Negative & Negative \\
\hline 2 & Blood-stained & Exudative & 53.3 & 221 & 0.26 & 1.35 & 62 & Negative & Positive \\
\hline 3 & Yellow & Exudative & 48.8 & 220 & 5.95 & 5.93 & 81 & Negative & Negative \\
\hline 4 & Yellow & Exudative & 43.0 & 134 & 7.70 & 1.50 & 85 & Negative & Negative \\
\hline 5 & Yellow & Exudative & 64.0 & 226 & 5.72 & 1.60 & 80 & Negative & Negative \\
\hline 6 & Blood-stained & Exudative & 53.2 & 144 & 7.35 & 8.00 & 85 & Negative & Negative \\
\hline 7 & Yellow & Exudative & 25.2 & 212 & 4.16 & 2.98 & 70 & Negative & Negative \\
\hline 8 & Blood-stained & Exudative & 35.4 & 205 & 5.61 & 5.10 & 85 & Negative & Negative \\
\hline 9 & Yellow & Exudative & 35.0 & 174 & 5.39 & 6.41 & 87 & Negative & Negative \\
\hline 10 & Blood-stained & Exudative & 29.8 & 213 & 8.86 & 6.50 & 79 & Negative & Negative \\
\hline
\end{tabular}

LDH, lactate dehydrogenase.
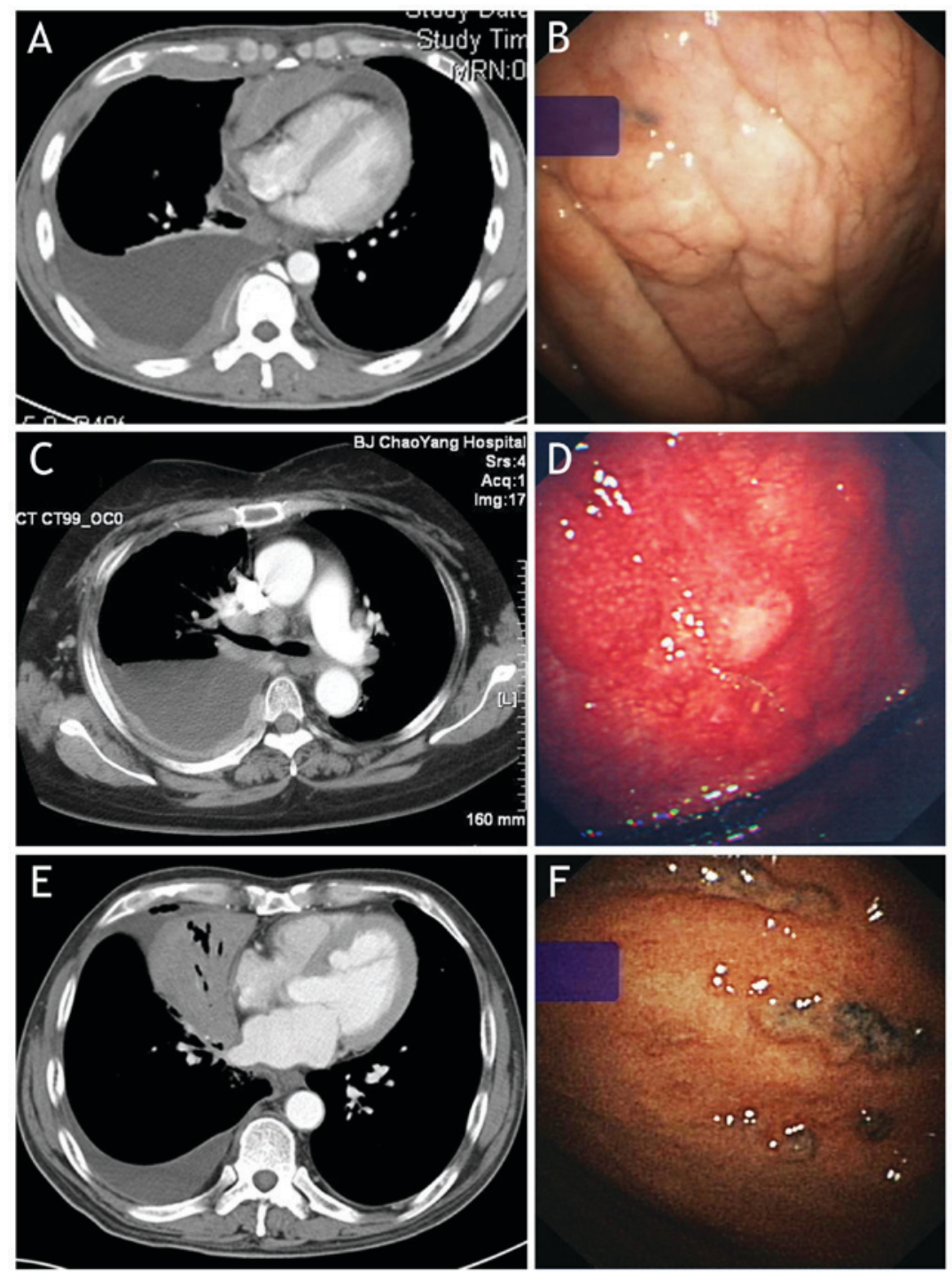

Figure 1. Abnormalities observed on contrast-enhanced CT (left panels) and under medical thoracoscopy (right panels) in patients with malignant pleural effusion induced by non-Hodgkin's lymphoma. (A) CT reveals diffuse pleural thickening and pleural nodules in the right hemithorax; (B) thoracoscopy of the same patient of (A) reveals diffuse pleural thickening on parietal pleura. (C) CT reveals diffuse pleural thickening and nodules in the right hemithorax; (D) thoracoscopy of the same patient with (C) reveals diffuse pleural thickening, scattered nodules and hyperemia on the parietal pleura. (E) CT reveals isolated pleural effusion in right hemithorax and lung atelectasis of the right middle lobe, with no discernible pleural abnormalities; (F) thoracoscopy of the same patient with (E) reveals small nodules with an irregular distribution on the parietal pleura. CT, computed tomography. 
Table IV. Characteristics of thoracoscopic findings $(n=10)$.

\begin{tabular}{cl} 
Patient no. & \multicolumn{1}{c}{ Thoracoscopic findings } \\
\hline 1 & $\begin{array}{l}\text { Pleural nodules, pleural plaques and pleural } \\
\text { hyperemia }\end{array}$ \\
2 & $\begin{array}{l}\text { Pleural nodules, pleural plaques and cellulose } \\
\text { Pleural thickening, pleural plaques and pleural } \\
3\end{array}$ \\
& adhesion \\
4 & Pleural nodules, pleural thickening and pleural \\
& hyperemia \\
5 & Scattered pleural nodules \\
6 & Pleural adhesion, hyperemia, ulcer and scattered \\
& hemorrhagic spots \\
7 & Pleural nodules, hyperemia, ulcer and cellulose \\
8 & Pleural thickening and cellulose \\
9 & Pleural hyperemia and pleural nodules \\
10 & Pleural plaques
\end{tabular}

Procedural details: Pleural fluid removed, $1.45 \pm 1.05 \mathrm{ml}$; Parietal pleura biopsies, $\mathrm{n}=9 \pm 3$.

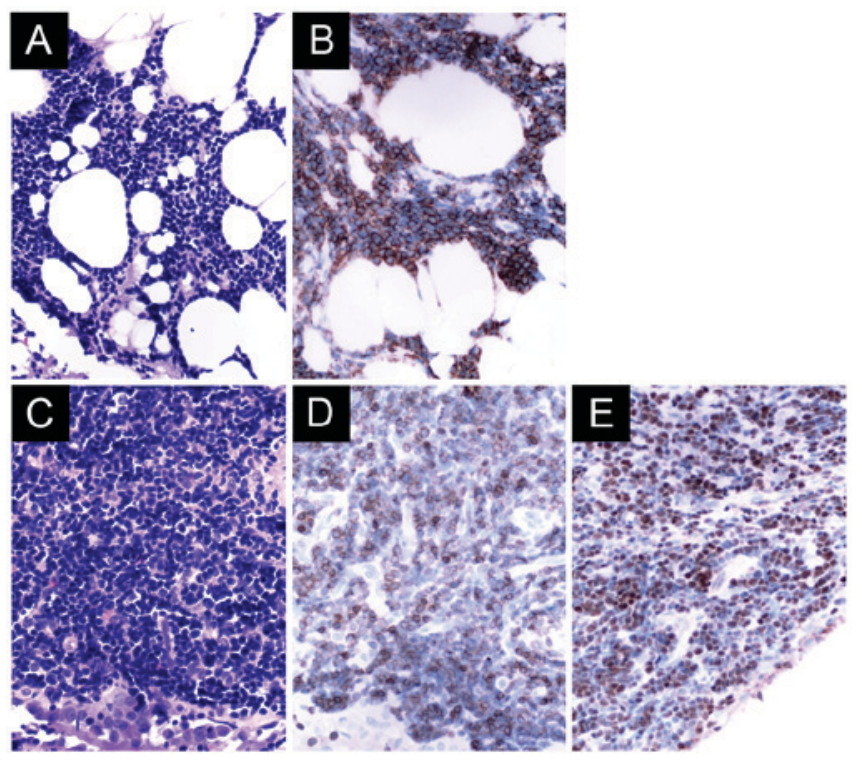

Figure 2. (A) Pleural biopsy from a patient with non-Hodgkin's extranodal marginal zone B-cell lymphoma reveals a diffused small cell neoplasm, with slightly irregular nuclei with moderately dispersed chromatin non-conspicuous nucleoli by $H \& E$ staining. (B) Immunohistochemistry reveals that the neoplastic cells were CD20-positive. (C) Pleural biopsy from a patient with non-Hodgkin's T-lymphoblastic lymphoma showing neoplastic cells of a small size with a high nuclear-to-cytoplasmic ratio and with condensed nuclear chromatin and no evident nucleoli by $\mathrm{H} \& \mathrm{E}$ staining. Immunohistochemistry shows that the neoplastic cells were (D) CD3-positive, and (E) terminal deoxynucleotidyl transferase-positive. Original magnification, $\mathrm{x} 400$ for all panels. H\&E, hematoxylin and eosin; CD20, cluster of differentiation 20.

was $(4.27 \pm 2.42) \times 10^{9} / 1$, with $80.2 \pm 5.3 \%$ lymphocytes. Cultures of pleural fluid samples from all patients failed to grow any infectious agents. Investigation of pleural fluid cytology for malignancy was non-diagnostic in 9 patients, with malignant cells found in the pleural fluid of 1 patient, but theirorigin and type could not be identified.
Under MT, one or more abnormalities could be observed on the surface of parietal and/or visceral pleura in each of the 10 patients studied. As shown in Fig. 1 and Table IV, pleural nodules were observed in 6 patients, hyperemia in 5 patients, plaque-like lesions in 4 patients, pleural thickening in 3 patients, cellulose in 3 patients, ulcer in 2 patients, adhesion in 2 patients and scattered hemorrhagic spots in 1 patient.

Histological and immunophenotyping studies. Histopathological examination revealed the presence of the following pathological findings (Fig. 2; Table V): i) The lymphoma cells infiltrate around reactive external B-cell follicles to a preserved follicle mantle in a marginal zone distribution and spread out to form larger confluent area; ii) diffused small cell neoplasms that have slightly irregular nuclei with moderately dispersed chromatin conspicuous or non-conspicuous nucleoli; iii) neoplastic cells of a medium size with a high nuclear-to-cytoplasmic ratio and with finely dispersed chromatin and relatively prominent nucleoli, or with condensed nuclear chromatin and no evident nucleoli; and iv) atypical lymphatic cell infiltrates in fibrous tissue.

Histopathological and immunophenotyping studies of pleural biopsy samples revealed extranodal marginal zone lymphoma of mucosa-associated lymphoid tissue (MALT lymphoma) in 5 patients, T-lymphoblastic lymphoma in 2 patients, diffuse large B-cell lymphoma in 1 patient, and small lymphocytic lymphoma in 1 patient. The pleural biopsy tissue was not sufficient for immunohistological staining in 1 patient, meaning a final diagnosis of follicular lymphoma was established by lymph node biopsy.

\section{Discussion}

The success of MT in diagnosing pleural lymphomas has been reported previously (13-15). Although the present study's sample size is relatively small, the current retrospective review is the first to specifically assess the utility of MT in the diagnosis of MPE induced by NHL. In the present study, the definite diagnosis of NHL in 9 out of 10 patients that presented with exudative lymphocytic pleural effusion was finally established though MT. These patients did not have any other indications of NHL based on medical history, physical examination, routine blood work and CT scans of the chest and abdomen; thoracentesis and/or closed pleural biopsy did not reach identify the cause of their MPEs.

CT findings in pleural NHL are similar to those in pleural metastasis or malignant mesothelioma (23-25). The present study revealed that, in addition to pleural effusion, NHL mainly appears as diffuse pleural thickening and localized nodules or masses on CT scans. The pattern of pleural thickening appeared continuous in 5 patients and discontinuous in 5 patients. In total, 5 patients had additional tumor nodules or masses of the pleura. It appears as isolated pleural effusion with no demonstrable pleural thickening or mass in 1 patient. A total of 6 patients had pulmonary consolidation/infiltration and 4 patients had mediastinal lymphadenopathy. Although thoracic CT findings are not specific and are not informative for the diagnosis of NHL, areas of pleural thickening or nodularity identified on CT scan can be used to guide subsequent biopsy and thus improve the diagnostic yield $(26,27)$. 


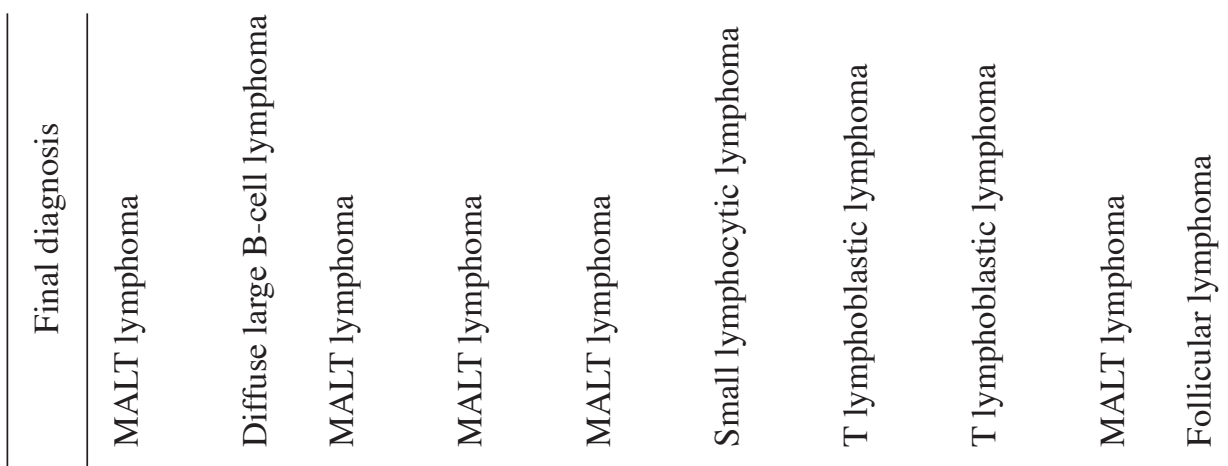

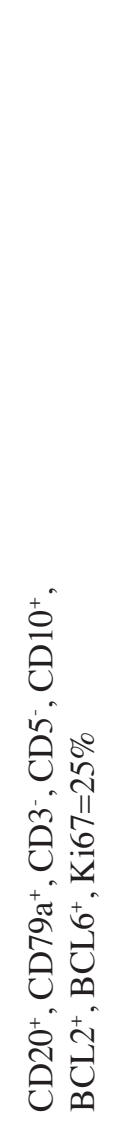

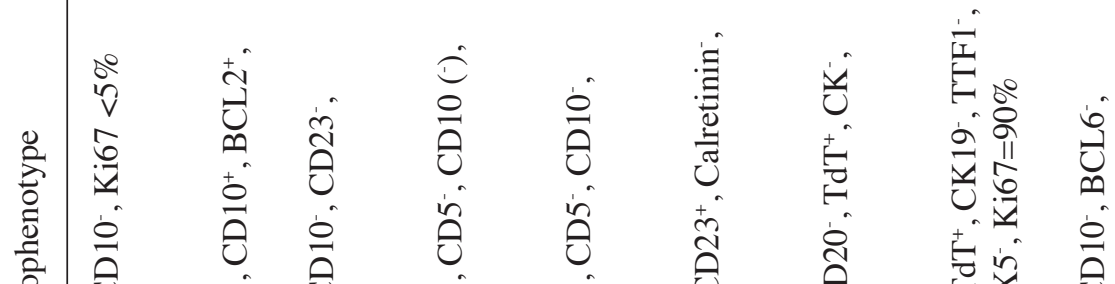

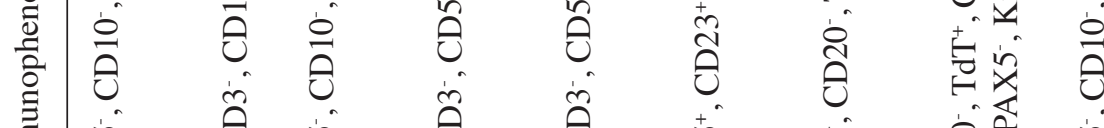

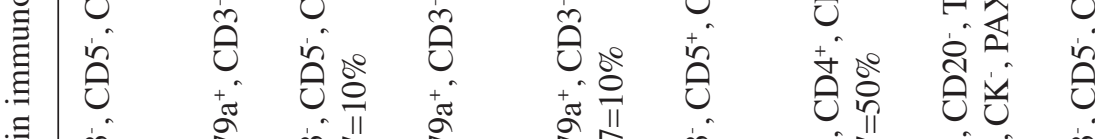

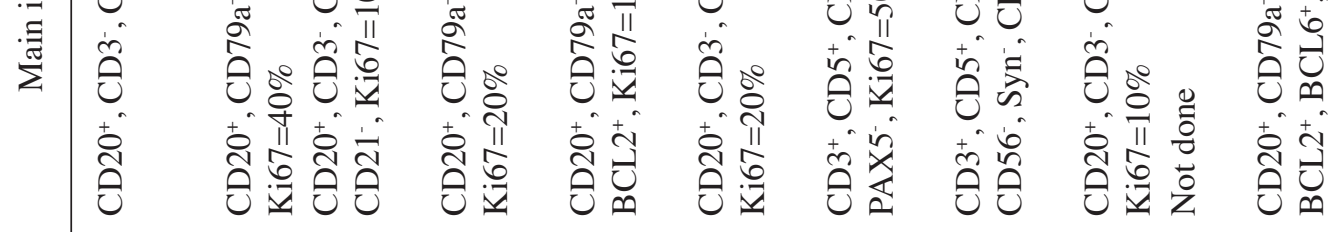

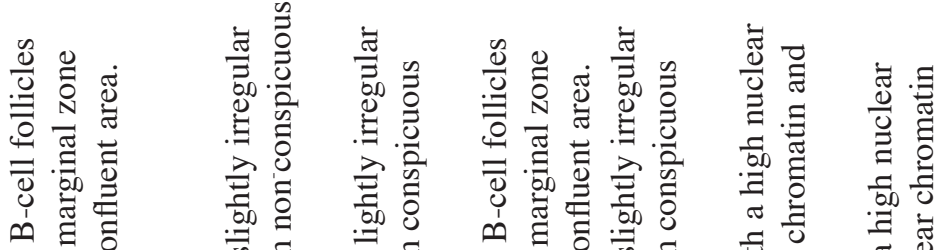

ค :

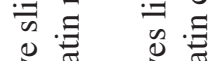

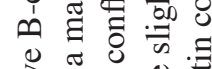

$\because \exists$

落

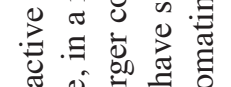

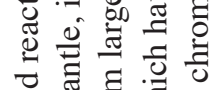

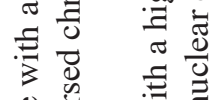

. 
Thoracentesis with pleural fluid cytology is usually an early step in diagnosing MPE. In cases of MPE induced by NHL, even experienced cytologists may not be able to make a definite diagnosis because: i) Lymphomatous cells in pleural fluid are always sparse $(4,28)$; ii) lymphomatous cells in pleural fluid are usually identical to lymphocytes in other tissues involved, such as lymph nodes $(4,29)$; and iii) difficulties in morphologically distinguishing lymphomatous cells from reactive lymphocytes arise in low-grade lymphomas, in which the involved cells are small mature lymphocytes, as well as whenever a mixed population of lymphomatous and reactive lymphocytes exists $(30,31)$.

The presence of malignant cells in the pleural fluid of a patient with NHL does not necessarily indicate pleural involvement with the tumor, as is invariably true in patients with metastatic carcinoma (32). As NHL lesions on the pleural surface are scattered, a closed pleural biopsy adds little to the diagnosis $(28,33)$. Previous studies have shown that real-time image-guided pleural biopsy is a promising technique for sampling the pleura, as it can improve MPE diagnostic sensitivity $(26,34,35)$. MT has been a routine method for patients with exudative pleural effusion that remain undiagnosed by clinical, radiologic, laboratory or cytological investigation in Beijing Chaoyang Hospital since June 2005. During this period, a total of 833 patients with undiagnosed pleural effusions underwent MT successfully, and 342 of them were eventually confirmed as having MPE (16).

Malignant neoplasm is the leading cause of death in the adult Chinese population (36). MPE occurs in up to $15 \%$ of patients with advanced malignancies (37). More recently, data show that in 342 patients with MPEs who underwent MT, the most frequent cause of MPE was lung cancer (67.8\%), followed by mesothelioma (10.2\%) and lymphoma (2.9\%) (16). Although any type of lymphoma can be involved in the pleura, diffuse large B-cell lymphoma is most common, followed by follicular lymphoma, at rates of 60 and $\sim 20 \%$, respectively (38). In the present study, histopathological and immunohistochemical staining of pleural biopsy samples obtained through MT confirmed MALT lymphoma in 5 patients, $T$ lymphoblastic lymphoma in 2 patients, diffuse large B-cell lymphoma in 1 patient, and small lymphocytic lymphoma in 1 patient. It is possible that if the 1 patient whose final diagnosis was based on lymph node biopsy had provided pleural biopsy tissue suitable for immunohistochemical study, MT would have also been able to establish a definite diagnosis of NHL by pleural biopsy examination. Regardless, the present study provided firm evidence to demonstrate that MT can reach a definite diagnosis of NHL in 9 out of 10 (90\%) patients with MPE.

Although cytological investigation with immunophenotyping of pleural fluid cells can be diagnostic of malignancy and of the lymphoma subtype (39) and cytogenetic analysis may further support the diagnosis and define other specific types of lymphomas $(31,39,40)$. However, because a diagnosis of NHL in all 10 patients with MPE was not initially considered, flow cytometry was not performed to investigate the immunophenotype of pleural fluid cells in the current study.

In NHL, lymphomatous deposits arise from lymphatic channels and lymphoid aggregates in the subpleural connective tissue below the visceral pleura (41). MPE may develop in patients with NHL by three different mechanisms: i) Pleural infiltration by NHL with shedding of cells into the pleural space; ii) lymphatic obstruction by NHL infiltration of pulmonary and mediastinal lymph nodes; and iii) obstruction of the thoracic duct, which results in chylothorax $(8,30)$. One observation of the present study is that extensive infiltration of NHL into the pleura indicates that the major mechanism for the development of MPE in NHL is the direct involvement of the pleura by NHL tissue, rather than obstruction to lymphatic flow.

The present study had three limitations: It was not a prospective study and as such all required data were collected and analyzed retrospectively; the sample size was quite small, with only 10 NHL patients with MPE being included; and only data from MPE patients with NHL, and no data from the other control group, such as the patients with benign pleural diseases, were available, meaning it was not possible to calculate the sensitivity and specificity of MT in diagnosing MPE induced by NHL.

In summary, MT is safe with a high positive rate of diagnosis of MPE induced by NHL. Its convenience and compatibility with existing bronchoscopy means the technique has the potential to be a more widely performed procedure. Therefore, it is worth actively pursuing for patients with suspected MPE, if the facilities to conduct MT are available.

\section{Acknowledgements}

The present study was supported in part by grants from National Natural Science Foundation of China (grant nos. 91442109, 31470883 and 81270149), and in part by the Key Project Of The Department Of Science And Technology, Beijing, China (grant no. D141107005214003).

\section{References}

1. Marel M, Stastny B, Melínová L, Svandová E and Light RW: Diagnosis of pleural effusions. Experience with clinical studies, 1986 to 1990. Chest 107: 1598-1603, 1995.

2. Johnston WW: The malignant pleural effusion. A review of cytopathologic diagnoses of 584 specimens from 472 consecutive patients. Cancer 56: 905-909, 1985.

3. Das DK: Serous effusions in malignant lymphomas: A review. Diagn Cytopathol 34: 335-347, 2006.

4. Alexandrakis MG, Passam FH, Kyriakou DS and Bouros D: Pleural effusions in hematologic malignancies. Chest 125: 1546-1555, 2004

5. Hunter BD, Dhakal S, Voci S, Goldstein NP and Constine LS: Pleural effusions in patients with Hodgkin lymphoma: Clinical predictors and associations with outcome. Leuk Lymphoma 55: 1822-1826, 2014

6. Wong FM, Grace WJ and Rottino A: Pleural effusions, ascites, pericardial effusions and Edema in Hodgkin's disease. Am J Med Sci 246: 678-682, 1963 .

7. Manoharan A, Pitney WR, Schonell ME and Bader LV: Intrathoracic manifestations in non-Hodgkin's lymphoma. Thorax 34: 29-32, 1979.

8. Berkman N, Breuer R, Kramer MR and Polliack A: Pulmonary involvement in lymphoma. Leuk Lymphoma 20: 229-237, 1996.

9. Cordier JF, Chailleux E, Lauque D, Reynaud-Gaubert M Dietemann-Molard A, Dalphin JC, Blanc-Jouvan F and Loire R: Primary pulmonary lymphomas. A clinical study of 70 cases in nonimmunocompromised patients. Chest 103: 201-208, 1993.

10. Nador RG, Cesarman E, Chadburn A, Dawson DB, Ansari MQ, Sald $\mathrm{J}$ and Knowles DM: Primary effusion lymphoma: A distinct clinicopathologic entity associated with the Kaposi's sarcoma-associated herpes virus. Blood 88: 645-656, 1996. 
11. Hengge UR, Ruzicka T, Tyring SK, Stuschke M, Roggendorf M, Schwartz RA and Seeber S: Update on Kaposi's sarcoma and other HHV8 associated diseases. Part 2: Pathogenesis, Castleman's disease, and pleural effusion lymphoma. Lancet Infect Dis 2: 344-352, 2002.

12. Aozasa K: Pyothorax-associated lymphoma. J Clin Exp Hematop 46: 5-10, 2006.

13. Steiropoulos P, Kouliatsis G, Karpathiou G, Popidou M and Froudarakis ME: Rare cases of primary pleural Hodgkin and non-Hodgkin lymphomas. Respiration 77: 459-463, 2009.

14. Oikonomou A, Giatromanolaki A, Margaritis D, Froudarakis M and Prassopoulos P: Primary pleural lymphoma: Plaque-like thickening of the pleura. Jpn J Radiol 28: 62-65, 2010.

15. Giardino A, O'Regan KN, Hargreaves J, Jagannathan J, Park D, Ramaiya $\mathrm{N}$ and Fisher D: Primary pleural lymphoma without associated pyothorax. J Clin Oncol 29: e413-e415, 2011.

16. Wang XJ, Yang Y, Wang Z, Xu LL, Wu YB, Zhang J, Tong ZH and Shi HZ: Efficacy and safety of diagnostic thoracoscopy in undiagnosed pleural effusions. Respiration 90 $251-255,2015$.

17. Wang Z, Tong ZH, Li HJ, Zhao TT, Li XY, Xu LL, Luo J, Jin ML, $\mathrm{Li}$ RS and Wang C: Semi-rigid thoracoscopy for undiagnosed exudative pleural effusions: A comparative study. Chin Med J (Engl) 121: 1384-1389, 2008.

18. Wang Z, Xu LL, Wu YB, Wang XJ, Yang Y, Zhang J, Tong ZH and Shi HZ: Diagnostic value and safety of medical thoracoscopy in tuberculous pleural effusion. Respir Med 109: 1188-1192, 2015.

19. Zelenetz AD, Abramson JS, Advani RH, Andreadis CB, Bartlett N, Bellam N, Byrd JC, Czuczman MS, Fayad LE, Glenn MJ, et al: Non-Hodgkin's lymphomas. J Natl Compr Canc Netw 9: 484-560, 2011.

20. Tan D, Tan SY, Lim ST, Kim SJ, Kim WS, Advani R and Kwong YL: Management of B-cell non-Hodgkin lymphoma in Asia: Resource-stratified guidelines. Lancet Oncol 14 e548-e561, 2013.

21. Moy MP, Levsky JM, Berko NS, Godelman A, Jain VR and Haramati LB: A new, simple method for estimating pleural effusion size on CT scans. Chest 143: 1054-1059, 2013.

22. Light RW, Macgregor MI, Luchsinger PC and Ball WC Jr: Pleural effusions: The diagnostic separation of transudates and exudates. Ann Intern Med 77: 507-513, 1972.

23. Parnell AP and Frew I: Case report: Non-Hodgkin's lymphoma presenting as an encasing pleural mass. Br J Radiol 68: 926-927, 1995.

24. Barahona ML, Dueñas VP, Sánchez MT and Plaza BV: Case report. Primary mucosa-associated lymphoid tissue lymphoma as a pleural mass. Br J Radiol 84: e229-e231, 2011.

25. Aquino SL, Chen MY, Kuo WT and Chiles C: The CT appearance of pleural and extrapleural disease in lymphoma. Clin Radiol 54 647-650, 1999

26. Maskell NA, Gleeson FV and Davies RJ: Standard pleural biopsy versus CT-guided cutting-needle biopsy for diagnosis of malignant disease in pleural effusions: A randomised controlled trial Lancet 361: 1326-1330, 2003.
27. Rahman NM, Ali NJ, Brown G, Chapman SJ, Davies RJ, Downer NJ, Gleeson FV, Howes TQ, Treasure T, Singh S, et al: Local anaesthetic thoracoscopy: British Thoracic Society Pleural Disease Guideline 2010. Thorax 65 (Suppl 2): ii54-ii60, 2010.

28. Celikoglu F, Teirstein AS, Krellenstein DJ and Strauchen JA: Pleural effusion in non-Hodgkin's lymphoma. Chest 101: 1357-1360, 1992.

29. Bangerter M, Hildebrand A and Griesshammer $M$ : Immunophenotypic analysis of simultaneous specimens from different sites from the same patient with malignant lymphoma. Cytopathology 12: 168-176, 2001.

30. Xaubet A, Diumenjo MC, Maŕin A, Montserrat E, Estopá R, Llebaría C, Austí A and Rozman C: Characteristics and prognostic value of pleural effusions in non-Hodgkin's lymphomas. Eur J Respir Dis 66: 135-140, 1985.

31. Pietsch JB, Whitlock JA, Ford C and Kinney MC: Management of pleural effusions in children with malignant lymphoma. J Pediatr Surg 34: 635-638, 1999.

32. Clarkson B: Relationship between cell type, glucose concentration, and response to treatment in neoplastic effusions. Cancer 17: 914-928, 1964.

33. Froudarakis ME: Diagnostic work-up of pleural effusions. Respiration 75: 4-13, 2008

34. Metintas M, Ak G, Dundar E, Yildirim H, Ozkan R, Kurt E, Erginel S, Alatas F and Metintas S: Medical thoracoscopy vs CT scan-guided Abrams pleural needle biopsy for diagnosis of patients with pleural effusions: A randomized, controlled trial. Chest 137: 1362-1368, 2010.

35. Koegelenberg CF, Bolliger CT, Theron J, Walzl G, Wright CA, Louw $\mathrm{M}$ and Diacon AH: Direct comparison of the diagnostic yield of ultrasound-assisted Abrams and Tru-Cut needle biopsies for pleural tuberculosis. Thorax 65: 857-862, 2010.

36. He J, Gu D, Wu X, Reynolds K, Duan X, Yao C, Wang J, Chen CS, Chen J, Wildman RP, et al: Major causes of death among men and women in China. N Engl J Med 353: 1124-1134, 2005.

37. Haas AR, Sterman DH and Musani AI: Malignant pleural effusions: Management options with consideration of coding, billing, and a decision approach. Chest 132: 1036-1041, 2007.

38. Vega F, Padula A, Valbuena JR, Stancu M, Jones D and Medeiros LJ: Lymphomas involving the pleura: A clinicopathologic study of 34 cases diagnosed by pleural biopsy. Arch Pathol Lab Med 130: 1497-1502, 2006.

39. Bangerter M, Hildebrand A and Griesshammer M: Combined cytomorphologic and immunophenotypic analysis in the diagnostic workup of lymphomatous effusions. Acta Cytol 45: 307-312, 2001.

40. Matolcsy A, Nádor RG, Cesarman E and Knowles DM: Immunoglobulin VH gene mutational analysis suggests that primary effusion lymphomas derive from different stages of $\mathrm{B}$ cell maturation. Am J Pathol 153: 1609-1614, 1998.

41. Dynes MC, White EM, Fry WA and Ghahremani GG: Imaging manifestations of pleural tumors. Radiographics 12: 1191-1201, 1992. 